\title{
BMJ Open Patient attitudes about the clinical use of placebo: qualitative perspectives from a telephone survey
}

\author{
Robin Ortiz, ${ }^{1}$ Sara Chandros Hull, ${ }^{2}$ Luana Colloca ${ }^{3}$
}

To cite: Ortiz R, Chandros Hull S, Colloca L. Patient attitudes about the clinical use of placebo: qualitative perspectives from a telephone survey. BMJ Open 2016;6:e011012. doi:10.1136/bmjopen-2015011012

- Prepublication history and additional material is available. To view please visit the journal (http://dx.doi.org/ 10.1136/bmjopen-2015011012).

Received 4 January 2016 Revised 29 February 2016 Accepted 8 March 2016

CrossMark

For numbered affiliations see end of article.

Correspondence to Dr Luana Colloca; colloca@ son.umaryland.edu

\section{ABSTRACT}

Objectives: To examine qualitative responses regarding the use of placebo treatments in medical care in a sample of US patients.

Survey studies suggest a deliberate clinical use of placebos by physicians, and prior research has found that although most US patients find placebo use acceptable, the rationale for these beliefs is largely unknown.

Setting: Members of the Outpatient Clinic at the Kaiser Permanente Northern California interviewed research participants who had been seen for a chronic health problem at least once in the prior 6 months. Participants: 853 women (61\%) and men, white (58\%) and non-white participants aged $18-75$ years. Primary and secondary outcomes: Qualitative responses on perceptions of placebo use from onetime telephone surveys were analysed for common themes and associations with demographic variables.

Results: Prior results indicated that a majority of respondents felt it acceptable for doctors to recommend placebo treatments. Our study found that a lack of harm $(n=291,46.1 \%)$ and potential benefit $(n=250,39.6 \%)$ were the most common themes to justify acceptability of placebo use. Responses citing potential benefit were associated with higher education $(r=0.787 ; p<0.024)$. Of the minority of respondents who judged it never acceptable for doctors to recommend placebo treatments, the most often referenced rationale was obligation of the doctor to do more $(n=102,48.3 \%)$. Additional themes emerged around the issue of whether a doctor was transparent about placebo use, including honesty, patient's right to know and power of the mind. Older age was associated with likelihood to cite overall physician, as opposed to treatment, related themes $(r=0.753 ; p<0.002)$.

Conclusions: Participants seem to appreciate and understand the lack of harm and potential benefit associated with placebo treatments, while valuing the role of the physician and the patient in its implementation.

\section{INTRODUCTION}

Placebos are substances and interventions that lack specific efficacy in treating a patient's condition based on the inherent properties of
Strengths and limitations of this study

This survey study offers a novel perspective on patients' views about placebo treatment, contributing to the discussion regarding the use of placebos in clinical practice.

- By enrolling a large and diverse patient population, this study identifies a difference in patients' views on the clinical use of placebo treatment depending on the level of transparency involved in their use.

- There are some limitations to this study, including the open coding analytic approach that can introduce reviewer biases.

the treatment. Placebo effects refer to neurobiological and clinical changes produced by a placebo administration (pure) or active treatment (impure) given in a certain context. ${ }^{1}$ Assuming that placebo effects can be harnessed to achieve better outcomes than usual medical care, whether and how physicians may recommend treatments that lack any specific efficacy remains controversial. $^{2-4}$ A number of studies have found that placebos are used by physicians across different countries, ${ }^{5-9}$ although these studies rarely distinguish between the nature of different kinds of placebos (eg, pure vs impure). ${ }^{10}$ More information regarding the views of physicians and patients, especially surrounding the concept of deception, would help inform the clinical use of placebos. ${ }^{11-15}$ Understanding patients' attitudes and perspectives might better guide ethical, and potentially beneficial, use of placebos. $^{16}$

A recent qualitative study identified that physicians feel that there is a lack of harm and even a potential benefit associated with placebo use, and that deception is essential to the definition of a placebo. ${ }^{11}$ Interestingly, non-clinicians feel that the potential benefit outweighs the importance of transparency in use. For example, our group previously identified such attitudes in the USA among patients, ${ }^{12}$ with $70 \%$ of patient respondents viewing placebo use acceptable in the case of 
deception, and approximately $79 \%$ in the case of transparency. ${ }^{12}$ However, although the study of physician attitudes assessed potential themes that may underlie these views, ${ }^{11}$ qualitative assessment of the rationale underlying patient attitudes is lacking.

Although placebo effects may be elicited in some cases even without the use of deception, ${ }^{17}$ a more in-depth understanding of patient views towards the risks and benefits of giving placebos clinically would still be useful to inform whether patients feel deception undermines their autonomy. ${ }^{15} 18{ }^{19}$ For example, it is unknown if patient interest in the potential therapeutic characteristics of placebo treatment might override autonomous considerations. Given these unknowns, current US guidelines require transparency in the use of placebo treatment.

In this study, our aim was to analyse qualitative data collected as part of a US national survey to uncover underlying patient attitudes about the use of placebo in the face of deception or transparency. Given the large size of this survey, we were also able to examine the relative frequencies of these attitudes and how demographic characteristics (eg, sex, age, race and level education) influence such attitudes. By categorising our findings by theme, we are able to understand more about the contribution of treatment and physician-patient relationship themes within participant responses. Finally, a brief content analysis for additional contributions to subject responses was performed.

\section{METHODS}

\section{Participant selection and recruitment and survey development and implementation}

Research participants were recruited through the member database of Kaiser Permanente Northern California. They were contacted by mail and invited to participate or opt out of our study. Those who had not opted out were contacted by telephone. A total of 853 participants participated in this telephone survey (53.4\% response rate). ${ }^{12}$

All research procedures were approved by the Kaiser Foundation Research Institute Institutional Review Board (IRB), CN-10AAvin-02-H, and classified as exempt from IRB review at the National Institutes of Health. Participants gave informed consent before taking part in the study. Respondents were compensated for their time after participating in the interview ( $\$ 20$ gift card).

The sample for this survey consists of adult members of Kaiser Permanente Northern California who had been seen in an outpatient clinic for a chronic health problem at least once in the prior 6 months. Respondents were women $(61 \%)$ and men $(39 \%)$, with an average age of 45 years. Fifty-eight percent were white and $42 \%$ were non-white. Forty-four percent had at least an undergraduate college education (table 1).

The survey was developed through a process that included patient focus groups in Baltimore, Maryland; expert review; and pretesting of the telephone interviews with 20 members of Kaiser Permanente Northern
Table 1 Participants' characteristics

Participants $(n=853)$

\begin{tabular}{lc}
\hline Sex & \\
Female & $524(61 \%)$ \\
Male & $329(39 \%)$ \\
Age & \\
$\quad$ Mean age (SD) & $45.1(15.7)$ \\
Race/ethnicity & \\
Based on OMB categories & \\
http://www.whitehouse.gov/sites/default/files/omb/assets/ \\
information_and_regulatory_affairs/re_app-a-update.pdf \\
White non-Hispanic & $486(58 \%)$ \\
African-American/Other black & $82(10 \%)$ \\
Hispanic/Latino & $132(16 \%)$ \\
Asian non-Hispanic & $121(14 \%)$ \\
American Indian or Alaska Native & $4(0.5 \%)$ \\
Native Hawaiian or other Pacific Islander & $7(1 \%)$ \\
Mixed & $10(1 \%)$ \\
Educational level & \\
Less than high school graduate & $13(2 \%)$ \\
High school graduate & $107(13 \%)$ \\
Some college & $316(37 \%)$ \\
College degree or beyond & $372(44 \%)$ \\
\hline OMB, Office of Management and Budget. &
\end{tabular}

California. The survey, which took respondents an average of $20 \mathrm{~min}$ to complete, was administered by trained (compensated) interviewers using a Computer-Aided Telephone Interview (CATI) system. Respondents were initially asked about their beliefs regarding the connection between the mind, body and illness, and their knowledge of placebos and the placebo effect. They were then provided with an operational definition of 'placebo treatment':

A patient experiences a placebo effect when they get better after taking a treatment, not because of the treatment itself, but because the patient expects they will benefit from the treatment. For the rest of this survey, we will ask you to assume that a placebo treatment is a treatment that only works because it can produce a placebo effect. Placebo treatments can be sugar pills or other treatments used to create a placebo effect.

This definition was based on previous surveys of physicians as well as our experience with patient focus groups. Following this explanation, we asked respondents about their beliefs regarding placebo mechanisms and the acceptability of doctors recommending placebo treatments, using both general questions and scenarios that varied the nature of the placebo treatment, the treatment indication and the manner in which the physician described the treatment to the patient. Respondents were randomised to two different scenarios, which varied according to whether or not the patient was aware that the doctor was recommending a placebo treatment (deception vs transparency), table 2. Respondents were also asked about their willingness to take placebos in 
Table 2 Survey scenarios and associated qualitative questions

\section{Scenario}

A 45-year-old man goes to his doctor because he's been having moderate stomach pains for the past month. After conducting the appropriate tests, the doctor feels confident that the problem is not serious, even though it's not clear what's causing the pain. The doctor decides to recommend a safe herbal treatment that does not contain anything likely to relieve the patient's symptoms, hoping that it might help by promoting a placebo effect. The doctor doesn't tell the patient that this is a placebo treatment, just that it's worth trying as some patients experiencing similar stomach pains get better after taking this treatment. So the patient doesn't know that the doctor is recommending a placebo treatment. The patient is told to call the doctor if he doesn't feel better after taking the medicine for 3 days.

A 45-year-old man goes to his doctor because he's been having moderate stomach pains for the past month. After conducting the appropriate tests, the doctor feels confident that the problem is not serious, even though it's not clear what's causing the pain. The doctor decides to recommend a safe herbal treatment. He tells the patient that this treatment does not contain any ingredients likely to relieve his symptoms, but it might help by promoting a placebo effect and that some patients experiencing similar stomach pains get better after taking this treatment. So the patient is aware that the doctor is recommending the medicine in order to bring out a placebo effect. The patient is told to call the doctor if he doesn't feel better after taking the medicine for 3 days.

\section{Question}

\begin{tabular}{|c|c|c|}
\hline & $\begin{array}{l}\text { Associated } \\
\text { scenario type }\end{array}$ & $\begin{array}{l}\text { Associated } \\
\text { scenario number }\end{array}$ \\
\hline $\begin{array}{l}\text { Do you think it was acceptable for the doctor to try a placebo treatment in this } \\
\text { situation? }\end{array}$ & $\begin{array}{l}\text { Deception and } \\
\text { transparency }\end{array}$ & 1 and 2 \\
\hline $\begin{array}{l}\text { If this placebo treatment worked and the patient asked what the medicine was, do you } \\
\text { think the doctor should tell the patient that it was a placebo? }\end{array}$ & Deception & 1 \\
\hline $\begin{array}{l}\text { If you were the patient, would you be willing to take the treatment described in this } \\
\text { way? }\end{array}$ & Transparency & 2 \\
\hline
\end{tabular}

different scenarios. Participants were then asked qualitative open-ended 'why?' questions to support their responses. The survey methodology is illustrated in more detail elsewhere ${ }^{12}$ and described in accordance with the consolidated criteria for reporting qualitative research (COREQ). ${ }^{20}$ Qualitative data were collected via openended questions related to each of the scenarios presented in table 2 that were designed to explore patient beliefs and values regarding placebo treatments. The responses to these items were transcribed verbatim into a spreadsheet by the telephone interviewers during the interviews.

\section{Data capture, coding and analysis of qualitative data}

Thematic coding of the data was carried out through an iterative open coding process. An initial set of labels was generated after review of a random set of responses, which were then consolidated and organised to form a codebook. Participants who did not give an answer to the open-ended question or who answered with a response that did not fit under a defined theme were coded as 'null code'. Of the 853 responses, only 24 (2.8\%) were considered null codes, mostly responses such as 'I don't know'. Similar codes were grouped into categories according to whether they identified treatment-related or physician-related themes. All of the responses were coded by a primary reviewer ( $\mathrm{RO})$, and a secondary reviewer (SCH and LC) to assess concordance, which was high. A third independent coder was brought in to help resolve any discrepancies (FGM). After thematic coding was complete, content analysis was also performed to account for any possible themes that were missed using the inducting coding approach and to ensure that saturation of themes had been achieved. ${ }^{21}{ }^{22}$ The responses were reviewed again for repetitive simple phrases or keywords.

\section{Statistical analysis}

Descriptive statistics were performed to determine theme frequency by scenario and question (figure 1). The most commonly occurring themes were then analysed through logistic regression to test for associations between specific theme occurrence (dependent variable) and demographic (age, sex, race and education, respectively). Adjustments for multiple comparisons were made through Bonferroni correction and $\mathrm{p}$ less than 0.0125 was considered significant. Analyses were calculated using IBM SPSS software V.21.

\section{RESULTS}

Ten overall themes were extracted from the qualitative responses (table 3). Five were related to placebo treatment 
Level 1:

All participants, $n=853$

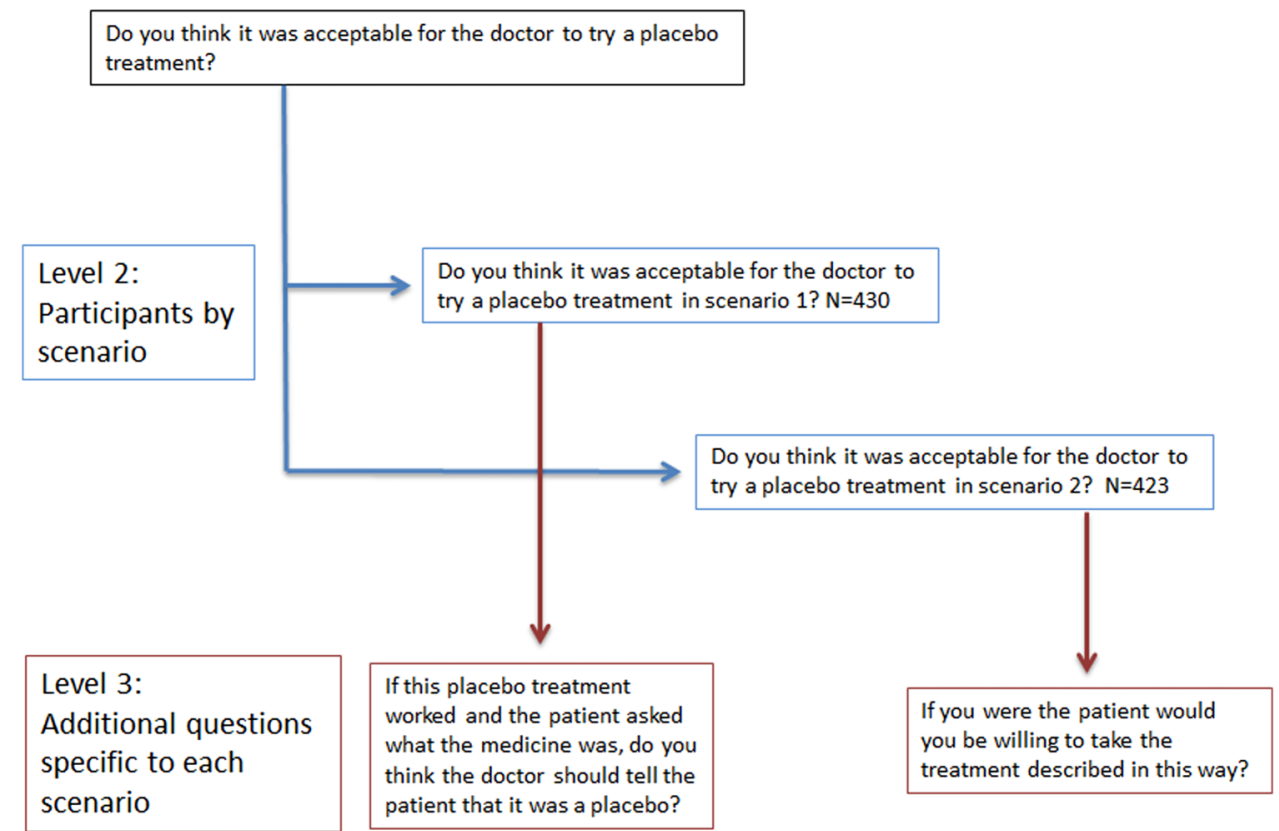

Figure 1 Design diagram. Respondents were asked about their beliefs regarding the acceptability of doctors recommending placebo treatments, using both general questions (level 1) and scenarios (levels 2). Respondents were also asked about their willingness to take placebos in the different scenarios (level 3).

characteristics and five were related to characteristics of the physician.

As reported previously, ${ }^{12}$ most respondents felt it was acceptable for a physician to use a placebo, ranging from 50 to $85 \%$ in various scenarios. Most respondents believed that a person's mind can influence clinical care and outcomes (85-96\%). Approximately $80-86 \%$ of respondents believed that deception is necessary for a placebo effect to take place. However, when given evidence of a prior study demonstrating placebo efficacy without deception, more than half of the respondents felt that a placebo for such an ailment might work. Respondents favoured physician honesty after a placebo effect is elicited in a patient. Finally, participants reported that they would be willing to take a placebo, whether they knew they were being offered a placebo $(62 \%)$ or were unaware $(65 \%)$.

\begin{tabular}{ll} 
Table 3 Themes of qualitative analysis & \\
\hline Themes & \\
\hline Treatment related & Doctor related \\
\hline Lack of harm & Honesty \\
Potential benefit & Dishonesty \\
Power of the mind & Patient right \\
Potential harm & Obligation \\
Lack of benefit & Trust \\
\hline
\end{tabular}

\section{Reactions to placebo use: reasons for acceptability}

The majority of participants who believed that placebo use is acceptable reported lack of harm $(n=291,46.1 \%$ of the participants) and potential benefit $(n=250,39.6 \%)$ as prominent themes. Lack of harm and potential benefit were highlighted both in the case of placebos being given deceptively, as in scenario $1 \quad(n=156,51.8 \%$ and $n=130$, $43.2 \%$ of the participants, respectively) and transparently by the physician, as in scenario $2(n=133,40.3 \%$ and $n=120$, $36.4 \%$, respectively). Importantly, participants clarified that lack of harm should include consideration of the fact that a serious condition had been ruled out $(\mathrm{n}=134,21.2 \%)$, that the placebo itself lacks harm or adverse effects $(\mathrm{n}=100,15.8 \%)$, and that there was a plan to follow up with the physician after 3 days $(n=54,8.6 \%)$. Examples of participants' answers are presented below:

\section{Lack of harm}

- “...because it is safe" (scenario 1)

- “...because the patient's issues were fully assessed... it was not serious... and there was a three day follow-up" (scenario 2)

\section{Potential benefit}

- "...because there is something in the herb that would help in a way normal medications could not help" (scenario 1)

- "...because there is a chance it might work... it is safe, why not?" (scenario 2) 
Reactions to placebo use: reasons for unacceptability

Respondents who felt it was unacceptable for the doctor to give the patient a placebo treatment most often expressed the belief about an obligation of healthcare providers to do more ( $\mathrm{n}=102,48.3 \%$ of the participants). This view was present in both the cases of deception as in scenario $1(\mathrm{n}=61,49.2 \%)$ and transparency by the physician as depicted in scenario $2(\mathrm{n}=39,43.3 \%)$ as follows:

\section{Scenario 1}

- "I would prefer to seek further what is causing the problem"

\section{Scenario 2}

- “...because the patient still wasn't diagnosed"

- "...because there might be something really wrong and the doctor should do more tests"

\section{Attitudes towards deception, scenario 1}

After taking into account the most common themes overall in the two scenarios-that is, lack of harm, potential benefit and obligation to do more-additional attitudes related to the deceptive scenario (scenario 1) were explored. Respondents in scenario 1 referred to the power of the mind ( $n=44,13.3 \%$ of the participants) when they found use of placebos as acceptable, while dishonesty $(n=33,26.6 \%)$ and potential for harm $(n=21,16.9 \%)$ were key concerns for respondents who reported the use of placebos as unacceptable. Examples are as follows:

\section{Power of the mind}

- “...because you never know how a body will react to a placebo treatment and since I believe in mind over matter, it might work"

- "It's possible the patient would have good effects because it's in his mind"

- "It might help the patient by reducing the patient's stress level, which may help his stomach pains"

\section{Dishonesty}

- "...doctor needs to be truthful, no matter what"

- "I don't like the whole idea of lying to the patient"

- "...because if someone comes in with a problem the doc should... not give a placebo... it's like a trick"

\section{Potential for harm}

- “...in a lot of situations, even though it doesn't seem serious, it really is"

- "What if they had something really serious?"

\section{Attitudes towards transparency, scenario 2}

In scenario 2, which presents the transparent use of placebo, participants who found the use of placebo acceptable identified honesty $(n=89,27 \%)$ as the prevalent reason. In contrast, lack of benefit was the prevalent reason among participants who did not consider the use of placebo acceptable $(n=32,36.8 \%)$. Some of their reasoning is exemplified below:
Honesty

- “...because he did not say or imply it was or wasn't a placebo, he just stuck to the facts ie, might work"

- “...because he was upfront about it"

\section{Lack of benefit}

- “...because if the patient knows it's not real, it won't work"

- "If you tell the patient that it is a placebo, then the placebo would not work"

- "If the person knows it's a placebo, it won't have any effect"

\section{Participants' perspective on disclosure of the use of placebos}

In addition to the general thoughts on use of placebos, participants were asked about their opinions towards disclosing the use of a placebo. Specifically, participants who were provided with scenario 1 were asked: 'If this placebo treatment worked and the patient asked what the medicine was, do you think the doctor should tell the patient that it was a placebo?'. The majority of respondents felt that the patient should be told that a placebo was used if they were to get well $(n=316,74.7 \%$ of participants). The rationale given by these participants who felt that the patient should be told about the use of a placebo was grounded to three themes. The patient's right to know $(\mathrm{n}=145,45.9 \%)$ was identified as the most frequent reason, but also honesty $(n=119$, $37.7 \%)$ and power of the mind $(\mathrm{n}=54,17.1 \%)$ were important considerations:

\section{Patients' rights}

- "...they have the right to know what they are taking"

- "...so the person could understand the effect of mind over body"

- "People deserve the right to know"

- "The patient has the right to know the outcome"

A minority of participants $(\mathrm{n}=107,25.3 \%)$ felt that the patient should not be informed of the use of placebos. For these respondents, common themes were pertinent to potential harm $(\mathrm{n}=40,37.4 \%)$, obligation to do more $(n=26,24.3 \%)$ and lack of benefit $(n=21,19.6 \%)$ :

\section{Potential harm}

- “...it could...backfire and the patient would not think it was any good"

- "...it may possibly distress the patient"

- "...because the patient would be mad"

- “...because the next time the patient will think any medication is a placebo"

- “...what you don't know can't hurt you”

\section{Obligation to do more}

- "...the doctor...has an obligation to tell what it truly was" 
Lack of benefit

- "...because it only works when the patient thinks it's a real medicine"

- "...because if the doctor is put in the position to tell the truth, he must...and especially if it worked the patient would learn about mind-body healing"

For those respondents who were surveyed with the transparent scenario 2, an additional question was posed: "If you were the patient would you be willing to take the treatment described in this way?"

A majority of respondents felt that they would take the placebo under these circumstances $(n=268,64 \%)$. The most common themes for these participants included potential benefit $(n=128,47.8 \%)$ followed by lack of harm $(n=100,37.3 \%)$ and trust $(n=45,16.8 \%)$. Some examples are shown below:

\section{Potential benefit}

- If I were the patient I would do what I have to do to get relief"

\section{Potential benefit and lack of harm}

- "I could be helped and it wouldn't harm me"

- “...if it's going to help me feel better, why not?"

Trust

- "...Even if I knew it was placebo, I would still do it because I would have faith in my doctor"

- "I have had good experience with my doctors, so I trust they will make the best decision with the information they have"

A minority of participants would not take the placebo themselves $(n=142,33.9 \%)$. For these participants, they reasoned that lack of benefit $(n=69,48.6 \%)$ and obligation to do more $(n=25,17.6 \%)$ were causes for their decision. Of note, a subset of the 69 participants whose responses cited lack of benefit also included a theme of power of the mind $(n=23,16.2 \%)$ in their response:

\section{Lack of benefit}

- "I wouldn't take it if I knew it was a placebo as it is contradictory to what a placebo treatment is, i.e. if I was told it was a placebo, I don't believe it would work"

- "I doubt it would work"

\section{Obligation to do more}

- "...because if I knew the doctor wasn't sure of the cause of pain, I would was more tests. Also, if I knew it was a placebo, it probably wouldn't benefit me"

\section{Overall themes}

We also grouped the themes into those relating to characteristics of the placebo treatment and physician. When asked about patient use of placebo in either scenario, responses tended to equally focus on both placebo treatment-related and physician-related themes (figure 2). Responses related to characteristics of the placebo

treatment were $52 \%$ of the total responses provided for scenario 1 (Deception), and $47 \%$ in scenario 2 (Transparency), respectively (figure 2). However, when participants assigned to scenario 1 were asked if a patient who had been given a placebo deceptively should be informed about the use of a placebo, the majority of responses focused on themes related to the physician (57\%, figure 2) and participants thought that physicians should not lie when actively asked by the patients. Regardless of scenario or question, a subset of responses suggested themes related to both the placebo treatment and the physician (14-19\%, figure 2).

We finally tested whether any new themes emerged. In quantifying the appearance of additional keywords as part of the content analysis, common keywords or themes included: personal experience, financial, psychosomatic, herb, real, ethical, research, exception, last resort, complementary medicine (see online supplementary table S1).

\section{Examples as follows}

Personal experience

- "This is a fresh situation in my experience from dealing with my mother-in-law..."

Financial

- "If it doesn't work, the patient will be charged anyway"

- "The patient is paying for the medication"

Theme type found in responses to question:

"Do you think it was acceptable for the doctor to try a placebo treatment in this situation?"

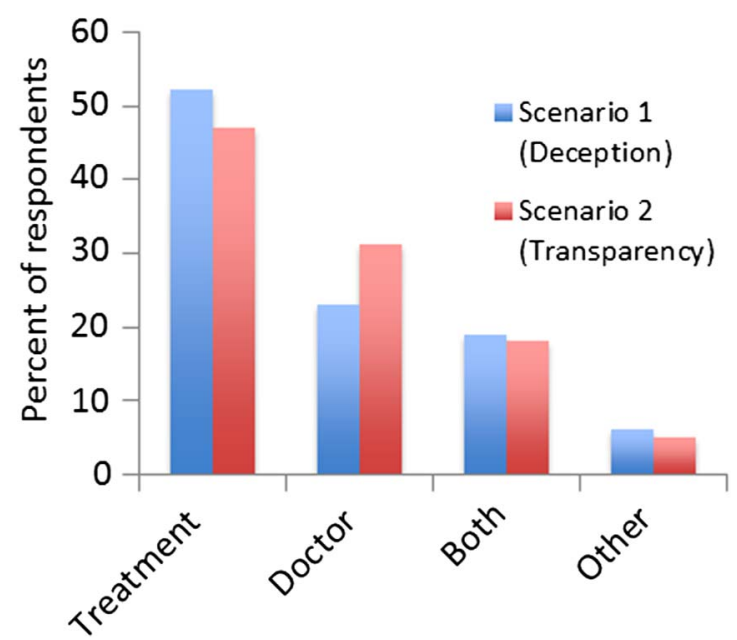

Figure 2 Response rate and themes. The graph summarises the theme category frequency in scenarios 1 and 2. Responses related to characteristics of the placebo treatment were $52 \%$ of the total responses provided for scenario 1 (Deception), and $47 \%$ in scenario 2 (Transparency), respectively. However, when participants assigned to scenario 1 were asked if a patient who had been given a placebo deceptively should be informed about the use of a placebo, the majority of responses focused on themes related to the doctor and patients thought that doctors should not lie when actively asked by the patients. 
Psychosomatic

- “...he's a hypochondriac..."

- “...feels it could be psychosomatic..."

Complementary medicine

- “...I'm all for alternative medicine..."

- "I believe in holistic meds"

Guinea pig

- "...seems like he is using the patient as a guinea pig"

- "placebos should only be used in research"

\section{Overall themes and demographics}

Overall, there were no statistically significant associations between demographic variables (age, sex and race) and the occurrence of the aforementioned themes. However, regardless of scenario (deception or transparency of placebo use), for responses that favoured acceptability of placebo, the tendency to mention the theme 'potential benefit' was associated with higher level of education under the transparent use of placebos, when controlling for other demographic factors including age, race and sex (scenario 2, respondents with some college degree $(\mathrm{r}=0.787 ; \mathrm{p}<0.024)$. Interestingly, older respondents were most likely to report a physician-related theme $(\mathrm{r}=0.014$; $\mathrm{p}<0.003$ ), and respondents with higher education were most likely to indicate themes related to treatment $(\mathrm{r}=0.753 ; \mathrm{p}<0.002)$, when controlling for other demographic factors including race, sex and education.

\section{DISCUSSION}

In this study, we analysed qualitative responses on perceptions of placebo use from one-time telephone surveys conducted in a diverse patient population to examine common themes and their associations with demographic variables. We identified lack of harm and potential benefit as the most common themes to justify acceptability of placebo use. Of the minority of respondents who judged it never acceptable for doctors to recommend placebo treatments, the majority referred to the doctors' obligation to do further clinical tests. Additional themes focused on honesty, the patient's right to know, and the power of the mind as critical factors for using placebos. The demographic characteristics that emerged as relevant were the level of education and age. Those participants with higher education mentioned potential benefit as a reason to justify placebo use. Older age was associated with the likelihood of identifying overall physician-related themes, as opposed to treatment-related themes.

In addition to their general thoughts on use of placebos, participants were asked their opinions about disclosing the use of a placebo. Importantly, the majority of respondents thought that physicians should not lie to them when actively asked by the patient, a view that was based on the patient's right to know, the value of honesty and the chance to harness the power of the mind. Only a minority of participants felt that the patient should not be informed of the use of placebos for reasons related to potential harm, obligation to do more and potential lack of benefit in being told about the use of a placebo.

The frequencies of the themes 'treatment' and 'doctor' were equally distributed when participants were asked about the general acceptability of placebo use. However, when confronted with a deceptive context, participants responded to themes related to doctor and trust. Indeed, when confronted with scenarios in which study participants were asked to image themselves in a particular clinical circumstance, interestingly, participants applied the same rationale about the use of placebos for themselves as they did for the hypothetical patient in the scenario.

Our findings describing patient attitudes about placebo use parallel physician attitudes. A recent study identified that common themes related to placebo use, including lack of harm and potential benefit, were identified by physicians in similar ways to those identified by participants in our study. ${ }^{11}$ It may also be the case that both participants and physicians feel that deception is necessary for placebo. In our study, respondents who felt that the patient should not be told that they were given a placebo often cited potential lack of benefit of future placebo use, due in part to the belief that the power of the mind benefit may depend on the deception. According to Bishop et $a l^{11}$ physicians in the UK still see deception as a feature of placebo uses. Notably, our results point to a surprising nuance in patients' attitudes towards use of placebo in the sense that deception, based on different survey scenarios, does not affect considerations of whether or not one would consider placebo use. Rather, patients prefer to be told about the use of placebos.

The observation that reasons such as lack of harm and potential benefit justify use of placebo treatment suggests that patients tend to focus on treatments and outcomes. ${ }^{23}$ The common response of potential benefit suggests that the patient seeks a treatment based on the expectation of benefit, despite knowing that a placebo is an inert substance. ${ }^{24}{ }^{25}$ Further, those who perceive placebo treatment as unacceptable mainly feel that this is due to the physician's obligation to do more, such as further diagnostic strategies or attempts to treat with an active, rather than inert, ingredient or modality. This suggests that an even greater number of individuals may view placebo treatment as acceptable, if further obligations are met-and may reflect that patients have preexisting anxiety about not having a diagnosis ${ }^{26}$ that potentially drives increased medical testing of physicians. ${ }^{27}$ When physicians meet these additional expectations, patients feel more satisfied, ${ }^{28}$ and potentially will then feel comfortable with placebo treatment. However, some still view that placebo treatment may not be acceptable if a physician is dishonest. Recent discussions about 'authorised deception' might offer a solution to concerns about dishonesty by alerting patients that they may be deliberately deceived, further permitting physicians 
to better inform patients of potential benefits and associated risks. $^{29}$

In the case of transparency, participants appear to worry that being aware of placebo use will lead to a lack of benefit through loss of the 'power of the mind', or mind-body effects. However, recent clinical results show that honest descriptions do not necessarily preclude the placebo effect. ${ }^{17}$ Also, individuals were more likely to identify trust as related to their own decision, compared to honesty as more relevant to the decision for others.

Respondents seemed to reflect more on the placebo treatment then the physician relationship, unless asked specifically if the patient should be informed of physician use of placebo. This indicates that respondents may be more concerned about the treatment itself when considering its use than with the physician or the circumstances of recommending a certain treatment. Responders were more concerned with the acts of the physician and the patient-doctor relation when asked about the physician's actions related to the treatment. Interestingly, those who focused on physician-related themes were of older age, which may be related to beliefs in more traditional models of care that hinge on a paternalistic, physician centred physician-patient relationship. ${ }^{30}$

We also observed that level of education might be associated with respondents' views of placebo use. Education level relates to health literacy, such that more educated respondents are more likely to be familiar with the medical literature, including about clinical trials, ${ }^{31} 32$ and the associated concepts of placebo. More educated individuals also tend to accept and use complementary medicine ${ }^{33}$ It is plausible to think that participants with higher education might be more familiar with nonpharmacological approaches as indicated by the recurrence of themes such as 'power of the mind' and 'alternative medicine' in various patients' responses. Further research is needed to explore these points further.

Finally, other considerations may be important to individuals when considering the use of placebo treatment including personal values such as personal experience, beliefs or ethical considerations. Still other influences may be financial considerations, views regarding the use of complementary, natural or holistic medicine or the practice of research.

There are some limitations to this study, related specifically to the qualitative methodology. The open coding analytic approach can potentially introduce reviewer bias. To minimise this possibility, multiple team members were involved in the interpretation of qualitative data and the refining of these codes. Ambiguous or unclear responses were also double coded, and discrepancies were further discussed among multiple coders. In addition, the methods used allow for the data to be interpreted without a priori assumptions, and additional analyses, including content analysis, allowed for the identification of themes that might not have been considered by initial coding. In addition, qualitative studies are often small and limited in their generalisability to other populations; however, a large (853 patients with chronic disease) and diverse (women and male, whites and non-whites, adults and elderly) patient population was enrolled in this study. Despite these limitations, this survey study offers a novel perspective on patient views about placebo treatment and contributes to the discussion regarding the use of placebos both in research and in clinical practice and processes such as informed consent.

\section{CONCLUSION}

This study is one of the largest to describe patient views about placebo treatment. Despite the numerous challenges and open questions for health providers and bioethicists, this study identifies common considerations around the themes of lack of harm and potential benefit of treatment, physicians' obligations to treatment and care and, to a lesser degree, honesty and trust of the physician as well as the power of the mind-body connection. Importantly, our study identifies that there is a difference in patients' views on the use of placebo treatment depending on the level of transparency involved in their use.

\section{Author affiliations}

${ }^{1}$ Medicine-Pediatrics Residency Program, Johns Hopkins Hospital, Baltimore, MD and National Institutes of Health, Bethesda, Maryland, USA

${ }^{2}$ National Institutes of Health and Department of Bioethics, Office of the Scientific Director, National Human Genome Research Institute, Clinical Center, National Institutes of Health, Bethesda, Maryland, USA

${ }^{3}$ Department of Pain Translation Symptom Science; School of Medicine, Department of Anesthesiology, University of Maryland, School of Nursing, Center to Advance Chronic Pain Research (CACPR), Baltimore, Maryland, USA

Acknowledgements The authors would like to thank Franklin G Miller for his helpful feedback in designing the study, identifying the themes for this study and serving as an independent coder.

Contributors RO served as the primary reviewer, analysed the data and drafted the first version of this manuscript. SCH designed the survey instrument, monitored the data collection and analysis for the survey scenarios, provided critical thoughts for coding the themes, served as the secondary reviewer and revised the paper. LC initiated the collaborative project, designed the survey instrument, monitored the data collection for the survey scenarios, analysed the data, served as the secondary reviewer and revised the paper. LC is the guarantor. All authors contributed equally. All authors, external and internal, had full access to all of the data (including statistical reports and tables) in the study and can take responsibility for the integrity of the data and the accuracy of the data analysis.

Funding This research was supported by the National Center for Complementary and Integrative Health ( $\mathrm{LC}$ and $\mathrm{SCH}$ ), the Clinical Center, the Intramural Research Program of the National Human Genome Research Institute ( $\mathrm{SCH})$, National Institutes of Health (RO), the National Institute of Dental and Craniofacial Research (1R01DE025946-01, LC) and the University of Maryland Baltimore (LC). The opinions expressed are those of the authors and do not necessarily reflect the policies or views of the National Institutes of Health or the Department of Health and Human Services. The study funders played no role in the study design; collection, analysis, and interpretation of data; writing of the report; or the decision to submit the article for publication. Researchers were independent of influence from study funders.

Competing interests NIH and UMB provided funding for submitted work. RO and $\mathrm{SCH}$ have no financial relationships with any organisations that might have an interest in the submitted work in the previous 3 years, and no other 
relationships or activities that could appear to have influenced the submitted work. LC serves as a consultant for Emmi Solution and gives educational lectures for Georgetown University.

Ethics approval Kaiser Foundation Research Institute Institutional Review Board (IRB), CN-10AAvin-02-H.

Provenance and peer review Not commissioned; externally peer reviewed.

Data sharing statement No additional data are available.

Open Access This is an Open Access article distributed in accordance with the Creative Commons Attribution Non Commercial (CC BY-NC 4.0) license, which permits others to distribute, remix, adapt, build upon this work noncommercially, and license their derivative works on different terms, provided the original work is properly cited and the use is non-commercial. See: http:// creativecommons.org/licenses/by-nc/4.0/

\section{REFERENCES}

1. Colagiuri B, Schenk LA, Kessler MD, et al. The placebo effect: from concepts to genes. Neuroscience 2015;307:171-90.

2. Comaroff J. A bitter pill to swallow: placebo therapy in general practice. Sociol Rev 1976;24:79-96.

3. Henriksen K, Hansen EH. The threatened self: general practitioners' self-perception in relation to prescribing medicine. Soc Sci Med 2004;59:47-55.

4. Colloca L. Ethics of placebos. Encyclopaedia of human biology. 3rd edn. Oxford, UK: Elsevier, 2014.

5. Nitzan U, Lichtenberg P. Questionnaire survey on use of placebo. BMJ 2004;329:944-6.

6. Kermen R, Hickner J, Brody $\mathrm{H}$, et al. Family physicians believe the placebo effect is therapeutic but often use real drugs as placebos. Fam Med 2010;42:636-42.

7. Fässler M, Meissner K, Schneider A, et al. Frequency and circumstances of placebo use in clinical practice-a systematic review of empirical studies. BMC Med 2010;8:15

8. Meissner K, Höfner L, Fässler M, et al. Widespread use of pure and impure placebo interventions by GPs in Germany. Fam Pract 2012;29:79-85.

9. Tilburt JC, Emanuel EJ, Kaptchuk TJ, et al. Prescribing "placebo treatments": results of national survey of US internists and rheumatologists. BMJ 2008;337:a1938.

10. Louhiala P. What do we really know about the deliberate use of placebos in clinical practice? J Med Ethics 2012;38:403-5.

11. Bishop FL, Howick J, Heneghan C, et al. Placebo use in the UK: a qualitative study exploring GPs' views on placebo effects in clinical practice. Fam Pract 2014;31:357-63.

12. Hull SC, Colloca L, Avins A, et al. Patients' attitudes about the use of placebo treatments: telephone survey. BMJ 2013;347:f3757.

13. Justman S. Placebo: the lie that comes true? J Med Ethics 2013;39:243-8.
14. Cohen S, Shapiro H. "Comparable placebo treatment" and the ethics of deception. J Med Philos 2013;38:696-709.

15. Gold A, Lichtenberg P. The moral case for the clinical placebo. $J$ Med Ethics 2014;40:219-24.

16. Colloca L, Miller FG. Harnessing the placebo effect: the need for translational research. Philos Trans $R$ Soc Lond B Biol Sci 2011;366:1922-30

17. Kaptchuk TJ, Friedlander E, Kelley JM, et al. Placebos without deception: a randomized controlled trial in irritable bowel syndrome. PLOS ONE 2010;5:e15591.

18. O'Neill O. Paternalism and partial autonomy. J Med Ethics 1984;10:173-8.

19. Brody $\mathrm{H}$. The lie that heals: the ethics of giving placebos. Ann Intern Med 1982;97:112-18.

20. Tong A, Sainsbury P, Craig J. Consolidated criteria for reporting qualitative research (COREQ): a 32-item checklist for interviews and focus groups. Int J Qual Health Care 2007;19:349-57.

21. Namey E, Guest G,Thairu L, et al. ed. Handbook for team-based qualitative research. Lanham, MD: Altamira Press, 2007: 137-63.

22. O'Brien BC, Harris IB, Beckman TJ, et al. Standards for reporting qualitative research: a synthesis of recommendations. Acad Med 2014;89:1245-51.

23. Himmel W, Lippert-Urbanke E, Kochen MM. Are patients more satisfied when they receive a prescription? The effect of patient expectations in general practice. Scand J Prim Health Care 1997;15:118-22.

24. Kirsch I. Response expectancy as a determinant of experience and behavior. American Psychologist 1985;40:1189-202.

25. Rescorla RA. Pavlovian conditioning. It's not what you think it is. Am Psychol 1988;43:151-60.

26. Nettleton S, Watt I, O'Malley L, et al. Understanding the narratives of people who live with medically unexplained illness. Patient Educ Couns 2005;56:205-10.

27. Haggerty J, Tudiver F, Brown JB, et al. Patients' anxiety and expectations: how they influence family physicians' decisions to order cancer screening tests. Can Fam Physician 2005;51:1658-9.

28. Bowling A, Rowe G, McKee M. Patients' experiences of their healthcare in relation to their expectations and satisfaction: a population survey. J R Soc Med 2013;106:143-9.

29. Miller FG, Wendler D, Swartzman LC. Deception in research on the placebo effect. PLoS Med 2005;2:e262.

30. Weiss GB. Paternalism modernised. J Med Ethics 1985;11:184-7.

31. Kickbusch IS. Health literacy: addressing the health and education divide. Health Promot Int 2001;16:289-97.

32. Utami D, Bickmore TW, Barry B, et al. Health literacy and usability of clinical trial search engines. J Health Commun 2014;19(Suppl 2):190-204

33. Neiberg RH, Aickin M, Grzywacz JG, et al. Occurrence and co-occurrence of types of complementary and alternative medicine use by age, gender, ethnicity, and education among adults in the United States: the 2002 National Health Interview Survey (NHIS) J Altern Complement Med 2011;17:363-70. 